\title{
Crack Susceptibility of Binary Aluminum Alloys during Solidification
}

\author{
JiangweiLiu ${ }^{a}$ and Sindo Kou ${ }^{\text {b,* }}$ \\ ${ }^{a}$ School of Energy Science and Engineering, Central South University, Changsha, 410083, China \\ ${ }^{\mathrm{b}}$ Department of Materials Science and Engineering, The University of Wisconsin, Madison, WI \\ 53706, United States
}

\begin{abstract}
Cracking can occur during solidification in welding and casting. The present study attempted to deal with some fundamental questions regarding the susceptibility to cracking during solidification. How does the phase diagram affect the crack susceptibility? Can back diffusion occur in welding? How is the dihedral angle related to bridging between grains? To help answer the questions, the maximum $\left|d T / d\left(f_{S}\right)^{1 / 2}\right|$ (T is temperature and $f_{S}$ fraction solid) was calculated, whose validity as the crack susceptibility index was verified recently. To deal with curved solidus and liquidus lines (i.e., variable equilibrium segregation coefficient $k$ ), $f_{S}$ was calculated as a function of $T$ by numerical integration instead of by a simple analytical equation
\end{abstract} for constant $k$. Based on the secondary dendrite arm spacing $\lambda_{2}$ in common $\mathrm{Al}$ arc welds and the $\lambda_{2}-t_{f}$ data of $\mathrm{Al}$ alloys ( $t_{f}$ is local solidification time), it was shown that back diffusion can occur in $\mathrm{Al}$ arc welding. Binary Al alloy systems were investigated over wide ranges of the eutectic temperature $T_{E}\left(229\right.$ to $548^{\circ} \mathrm{C}$ ) and $k$ (about 0 to 0.87 at $T_{E}$ ). It was shown thatwith a very low $T_{E}$ the crack susceptibility can still be relatively low if $k$ is very high at $T_{E}$ to increase the effect of back diffusion on crack susceptibility reduction, consistent with the lower crack susceptibility of Al-Mg and even Al-Zn than Al-Cu. With both a very low $T_{E}$ and a very lowkat $T_{E}$, however, the crack susceptibility can be very high, consistent with the severe crack susceptibility of Al-Sn. The effect of the curvature of the liquidus and solidus lines on the crack susceptibility was shown. A possible link between the dihedral angle and bridging between grains was also shown.

\footnotetext{
*Corresponding author.
} 


\section{Introduction}

Cracking during solidification can occur in welding, called solidification cracking [1], and in casting, called hot tearing [2-4]. The prominent RDG model of Rappaz, Drezet and Gremaud [5] was the first hot tearing model with a physically sound basis. However, the grain boundary, where cracking occurs, was not yet considered. As illustrated in Fig. 1, Kou [6] recently considered: 1 . separation of grains from each other under tensile strain to cause cracking, 2. growth of grains toward each other to bridge together to resist cracking, and 3. liquid feeding along the grain boundary to resist cracking. Since cracking occurs near $\left(f_{S}\right)^{1 / 2}=1\left(f_{S}\right.$ is fraction solid), based on the analysis of the space between two neighboring columnar dendritic grains in a volume element near $\left(f_{S}\right)^{1 / 2}=1$, the following criterion for cracking was derived:

$\left\{\frac{d \varepsilon_{\text {local }}}{d t}>\sqrt{1-\beta} \frac{d \sqrt{f_{S}}}{d T} \frac{d T}{d t}+\frac{d}{d z}\left[\left(1-\sqrt{1-\beta} \sqrt{f_{S}}\right) v_{z}\right]\right\}_{\sqrt{f_{S}} \rightarrow 1}$

(separation) (growth) (feeding)

where $\varepsilon_{\text {local }}$ : local tensile strain; $t$ : time; $\beta$ : solidification shrinkage; $T$ : temperature; $z$ : axial direction of columnar dendritic grains; $v_{z}$ : velocity of liquid feeding along the grain boundary. The three terms in Eq. (1) are all positive and they represent the strain rate, growth rate and feeding rate. Entrapped bifilms [3, 4], micro gas porosity [7] and the external surface [8] can act as the crack initiation sites. Coniglio and Cross [7] proposed the mechanisms of crack initiation and growth during solidification in welding.

Kou [6] showed that $\left|d T / d\left(f_{S}\right)^{1 / 2}\right|$ near $\left(f_{S}\right)^{1 / 2}=1$ of an alloy can be an index for its crack susceptibility. As illustrated in Fig. 1, a high $\left|d T / d\left(f_{S}\right)^{1 / 2}\right|$ near $\left(f_{S}\right)^{1 / 2}=1$ discourages the bridging together of neighboring columnar dendritic grains that is needed to resist cracking by slowing down the lateral growth rate $d R / d t$ of the grains, where $R$ is the characteristic radius of the grains. It also discourages the feeding of shrinkage that is needed to resist cracking by 
lengthening the grain-boundary channel to hinder liquid flow through the channel. As the grains keep growing longer in the axial direction, a small $d R / d t$ keeps the channel open and thus makes it long. The resistance to flow caused by the viscosity of liquid is higher with a longer channel [9].

Since the maximum $\left|d T / d\left(f_{S}\right)^{1 / 2}\right|$ occurs near $\left(f_{S}\right)^{1 / 2}=1$, it can be used as another form of the same index. The maximum $\left|d T / d\left(f_{s}\right)^{1 / 2}\right|$ is the maximum steepness of the slope of the curve of $T$ vs. $\left(f_{S}\right)^{1 / 2}$. The $T-\left(f_{S}\right)^{1 / 2}$ curve and hence its maximum $\left|d T / d\left(f_{S}\right)^{1 / 2}\right|$ can be calculated by using Pandat [10], PanAluminum [11] and the Scheil model (no diffusion). The validity of the maximum $\left|d T / d\left(f_{S}\right)^{1 / 2}\right|$ as the crack susceptibility index was verified by Kou [12]. First, a filler metal known to reduce the crack susceptibility of an alloy in welding, e.g., filler metal $4145 \mathrm{Al}$ for welding $2014 \mathrm{Al}$ and 4043 for welding $6061 \mathrm{Al}$, was shown to make the maximum $\left|d T / d\left(f_{S}\right)^{1 / 2}\right|$ of the weld significantly lower than that of the alloy. Second, the maximum $\left|d T / d\left(f_{S}\right)^{1 / 2}\right|$ was shown to increase in the order of 2219, 2014, 2024, 7075 and $6061 \mathrm{Al}$, consistent with their ranking of cracking in crack susceptibility tests. Third, the calculated crack susceptibility curves (maximum $\left|d T / d\left(f_{S}\right)^{1 / 2}\right|$ vs. solute content $C_{o}$ ) of binary Al-Si, Al-Cu and Al-Mg alloys were $\Lambda$-shaped as observed in crack susceptibility tests, and the most cracksusceptible solute contents were close to the observed ones. However, the predicted crack susceptibility of Al-Mg alloys was higher than that of $\mathrm{Al}-\mathrm{Cu}$ alloys, contrary to the better castability $[13,14]$ and weldability $[13,15]$ of Al-Mg alloys.

Liu and Kou [16] subsequently showed that due to the very high maximum Mg solubility $\left(C_{S M}=17.5 \mathrm{wt} \%\right)$ in solid $\mathrm{Al}$, back diffusion, if it occurs, can consume much $\mathrm{Mg}$ in the interdendritic liquid. To keep up with the liquid Mg content dictated by the phase diagram, $f_{S}$ at a given $T$ must rise to reject more $\mathrm{Mg}$ into liquid. Thus, the $T-\left(f_{S}\right)^{1 / 2}$ curves are shallower and the 
maximum $\left|d T / d\left(f_{S}\right)^{1 / 2}\right|$ smaller. This can explain the relatively low crack susceptibility of Al$\mathrm{Mg}$ alloys in spite of their wide freezing temperature range. To consider diffusion, the solidification path $f_{S}(T)$ was no longer based on the simple Scheil equation [2] but the analytical equation of Kurtz and Fisher [17]. Both equations require a constant equilibrium segregation coefficient $k$, that is, a binary alloy phase diagram with straight solidus and liquidus lines such as the Al-Si alloy system. This severely limits the number of binary Al alloy systems that can be studied.

The present study was conducted to investigate how the phase diagram affects the crack susceptibility of binary Al alloy systems, whether back diffusion can occur in Al arc welding, and how the dihedral angle is related to bridging between grains. In order to handle a variable $k$, numerical integration, instead of an analytical equation based on a constant $k$, was used to calculate $T$ vs. $\left(f_{S}\right)^{1 / 2}$ and hence the crack susceptibility.

\section{Numerical Integration of $C_{L}$ against $f_{S}$}

According to Kurtz and Fisher [17], the relationship between the solute content along the liquidus line $C_{L}$ and the fraction solid $f_{S}$ during solidification can be written as follows:

$$
\frac{d C_{L}}{(1-k) C_{L}}=\frac{d f_{S}}{1-(1-2 \alpha k) f_{S}}
$$

which, if $k$ is a constant, can be integrated from the initial solute content of the liquid $C_{o}$ at $f_{S}=0$ to become

$$
\frac{C_{L}}{C_{o}}=\left[1-\left(1-2 \alpha^{\prime} k\right) f_{S}\right]^{\frac{k-1}{\left(1-2 \alpha^{\prime} k\right)}}
$$

where

$$
\alpha^{\prime}=\alpha\left[1-\exp \left(-\frac{1}{\alpha}\right)\right]-\frac{1}{2} \exp \left(-\frac{1}{2 \alpha}\right)
$$


$\alpha=\frac{4 D_{S} t_{f}}{\lambda_{2}^{2}}$

$D_{S}$ : diffusion coefficient of solute in solid dendrites,

$t_{f}$ : local freezing (solidification) time, and

$\lambda_{2}$ :secondary dendrite arm spacing.

It has been shown that at $\alpha<0.1, \alpha$ is nearly identical to $\alpha$ ' in value $[16,17]$.

However, $k$ is usually not a constant for binary alloy systems, and Eq. (2) needs to be integrated numerically. Although with commercial thermodynamic software $k$ can be temperature-dependent $k$, the diffusion coefficient $D_{S}$ also becomes temperature-dependent. While the calculated results may be more precise, they cannot be shown by a dimensionless diffusion parameter such as $\alpha$, which can clearly demonstrate the effect of diffusion. With dimensional numbers, many more sets of results are needed to show what can be shown with a dimensionless number.

The numerical integration procedure is described as follows. First, the software Getdata Graph Digitizer [18] was used to trace the liquidus and solidus lines of the binary phase diagram and approximate them with a series of connected short segments along the lines from the melting point $T_{m}$ to the eutectic temperature $T_{E}$. Each segment was fitted with a polynomial equation. The number of segments $\mathrm{M}$ was smaller (e.g., 8 for $\mathrm{Al}-\mathrm{Cu}$ ) with slightly curved liquidus and solidus lines and larger (e.g., 28 for Al-Sn) with highly curved ones. The lengths of the segments were not uniform. It was found that linear equations (the simplest form of polynomial equations) were sufficient to trace the phase diagram. The segments were expressed as follows:

$$
\begin{aligned}
& C_{S}^{n}(T)=a_{S}^{n}+b_{S}^{n} T(\mathrm{n}=1,2,3 \ldots \mathrm{M}) \\
& C_{L}^{n}(T)=a_{L}^{n}+b_{L}^{n} T(\mathrm{n}=1,2,3 \ldots \mathrm{M})
\end{aligned}
$$


where $C_{S}$ and $C_{L}$ are,respectively, the solute contents along the solidus and liquidus lines, $T$ is temperature, and $a_{S}, b_{S}, a_{L}$ and $b_{L}$ are constants. The equilibrium segregation coefficient $k$ is defined as follows:

$k(T)=C_{S}(T) / C_{L}(T)$

Eq. (2) was integrated step by step from the initial solute content of the liquid $C_{o}$ at $f_{S}=0$. Substituting Eqs. (7)and(8) into Eq. (2),

$$
d f_{S}=b_{L}\left[\left(1-(1-2 \alpha k(T)) f_{S}\right] d T /\left[(1-k(T))\left(a_{L}+b_{L} T\right)\right]\right.
$$

based on which, the following equation can be written:

$$
f_{S}^{N}=f_{S}^{N-1}+\Delta f_{S}=f_{S}^{N-1}+b_{L}\left[\left(1-(1-2 \alpha k(T)) f_{S}^{N-1}\right] \Delta T /\left[(1-k(T))\left(a_{L}+b_{L} T\right)\right]\right.
$$

where $f_{S}^{N}$ is the fraction solid at the current temperature step and $f_{S}^{N-1}$ that at the previous temperature step. The temperature step $\Delta T$ was set at $0.01^{\circ} \mathrm{C}$ throughout the calculation, which took a few seconds to complete.

\section{Range of $\alpha$ relevant to $\mathrm{Al}$ arc welding}

Welding data have shown that a secondary dendrite arm spacing $\lambda_{2}$ of about $10 \mu \mathrm{m}$ is common in Al welds made by gas-tungsten arc (also called TIG) welding and that of about 20 $\mu \mathrm{m}$ is common in $\mathrm{Al}$ welds made by gas-metal arc (also called MIG) welding [16]. According to solidification data, for $\lambda_{2}=10$ to $20 \mu \mathrm{m}$ the local solidification timet $t_{f}$ is in the ranges of about 1 to $4 \mathrm{~s}$ for Al-Si alloys [19], 2 to $10 \mathrm{~s}$ for Al-Cu alloys [2, 20], and 1 to $7 \mathrm{~s}$ for Al-Cu-Mn alloys [21], the average being $t_{f}=1$ to $7 \mathrm{~s}$. Table 1 shows that, based on Eq. (5), the diffusion coefficient $D_{S}=1 \times 10^{-12} \mathrm{~m}^{2} / \mathrm{s}$ [22], and the range of $\alpha=0.025-0.050$, the corresponding $t_{f}$ is in the range of 0.625 to $5.00 \mathrm{~s}$, which is close to the $t_{f}$ range of 1 to $7 \mathrm{~s}$ for $\mathrm{Al}$ arc welds. Thus, back diffusion can occur in $\mathrm{Al}$ arc welding at the level of $\alpha=0.025$ to 0.050 , which will be used in the 
following discussion.

\section{Effect of curvature of liquidus and solidus lines}

It was found that the $T-\left(f_{S}\right)^{1 / 2}$ curves can be affected significantly by the curvature of the liquidus or solidus line. In Fig. 2 the Al-Cu system is used as an example for illustration. The Al$\mathrm{Cu}$ phase diagram in Fig. 2a was calculated using thermodynamic software Pandat [10] and aluminum database PanAluminum [11]. As shown, the liquidus line is slightly curved, and the solidus line is nearly straight. Assuming straight liquidus and solidus lines as an approximation, the $T-\left(f_{S}\right)^{1 / 2}$ curves were calculated without back diffusion $(\alpha=0)$ as shown in Fig. $2 b$. The $T$ $\left(f_{S}\right)^{1 / 2}$ curves in Fig. $2 \mathrm{~b}$ have been compared with those calculated using an analytical equation without diffusion, that is, the Scheil equation [16], and the two sets of curves are identical, thus verifying the validity of the numerical integration. The red lines in Fig. $2 \mathrm{~b}$ are the tangents to the $T-\left(f_{S}\right)^{1 / 2}$ curves at the locations of maximum steepness up to $\left(f_{S}\right)^{1 / 2}=0.99$.

In Fig. $2 \mathrm{c}$ the $T-\left(f_{S}\right)^{1 / 2}$ curves calculated based on the actual curved liquidus and solidus lines are superimposed on those from Fig. $2 \mathrm{~b}$ based on straight liquidus and solidus lines. As shown, there is a significant difference even though the actual liquidus lineis only slightly curved and the actual solidus line is nearly straight. With the curved liquidus and solidus lines, the maximum steepness $\left|d T / d\left(f_{S}\right)^{1 / 2}\right|$ of the curves increases to raise the crack susceptibility. The increase can be expected because the two-phase region of $(\mathrm{S}+\mathrm{L})$ in the phase diagram is widened. Thus, the equilibrium segregation coefficient $k$ is decreased to increase solute segregation and hence aggravate the crack susceptibility.

\section{Extensive bridging to resist cracking}

In the absence of back diffusion, for an alloy such as $\mathrm{Al}-0.1 \mathrm{Cu}$, a very small amount of liquid still remains when the eutectic temperature $T_{E}$ is reached. Such an alloy, like pure Al, is 
known to be resistant to cracking during solidification though the maximum steepness $\left|d T / d\left(f_{S}\right)^{1 / 2}\right|$ can be extremely high very near $\left(f_{S}\right)^{1 / 2}=1$ (e.g., 0.999). However, extensive bridging may have already occurred, e.g., at $\left(f_{S}\right)^{1 / 2}=0.99$, since the liquid left may no longer be enoughin quantity to form continuous films to separate grains. The fraction solid at which extensive bridging occurs to resist cracking will be called $f_{S B}[12,16]$. In the RDG model $[5]$ the crack susceptibility was assumed to end at $f_{S}=0.98$, that is, $f_{S B}=0.98$. In the model of Clyne and Davies [23], it was at $f_{S}=0.99$, that is, $f_{S B}=0.99$. Thus, $f_{S B}$ can be expected to be very close to 1.0, but its exact value may vary slightly from alloy to alloy. For the purpose of discussion, however, it is assumed that $f_{S B}=0.98$, and hence $\left(f_{S B}\right)^{1 / 2}=0.99$. Since extensive bridging occurs at $f_{S B}$ to end the crack susceptibility, beyond $f_{S B}$ the steepness $\left|d T / d\left(f_{S}\right)^{1 / 2}\right|$ is no longer relevant. Thus, if the steepness is still increasing beyond $f_{S B}$, such as the curve of $\mathrm{Al}-0.1 \mathrm{Cu}$, the steepness at $f_{S B}$ is taken as the maximum steepness $[12,16]$.

In Fig. 2b, the vertical dotted line indicates extensive bridging occurs at $\left(f_{S B}\right)^{1 / 2}=0.99$. The red lines are the tangents to the $T-\left(f_{S}\right)^{1 / 2}$ curves at the locations of the maximum steepness $\left|d T / d\left(f_{S}\right)^{1 / 2}\right|$.Before $\left(f_{S B}\right)^{1 / 2}=0.99$ the maximum steepness $\left|d T / d\left(f_{S}\right)^{1 / 2}\right|$ occurs at $T_{E}$ and it increases as the $\mathrm{Cu}$ content decreases from 7 to $1.5 \mathrm{wt} \%$. For alloys $\mathrm{Al}-1 \mathrm{Cu}, \mathrm{Al}-0.5 \mathrm{Cu}$ and $\mathrm{Al}-$ $0.1 \mathrm{Cu}$, the maximum steepness at $\left(f_{S B}\right)^{1 / 2}=0.99$ is considered and it decreases as the $\mathrm{Cu}$ content decreases from 1.0 to $0.1 \mathrm{wt} \%$. The $T-\left(f_{S}\right)^{1 / 2}$ curve of $\mathrm{Al}-1.3 \mathrm{Cu}$, if it was drawn, would pass through the intersection between $T_{E}$ and 0.99 and show the highest value of the maximum steepness. In other words, $\mathrm{Al}-1.3 \mathrm{Cu}$ is the $\mathrm{Al}-\mathrm{Cu}$ alloy that is most susceptible to cracking during solidification. If the maximum steepness was plotted $v s$. the $\mathrm{Cu}$ content, the resultant curve (called the crack susceptibility curve) would be $\Lambda$-shaped, with the peak at $1.3 \mathrm{wt} \% \mathrm{Cu}$.

\section{Al-Cu alloys}


The case of Al-Cu alloys is further shown in Fig. 3. The phase diagram in Fig. 3a shows that $T_{E}=548{ }^{\circ} \mathrm{C}$ and $k=0.170(=5.65 / 33.21)$ at $T_{E}$. The $T-\left(f_{S}\right)^{1 / 2}$ curves calculated previously in Fig. $2 \mathrm{c}$ based on the actual curved liquidus line but no diffusion $(\alpha=0.00)$ are superimposed on the curves calculated based on identical conditions except with diffusion $(\alpha=0.05)$. As shown in Fig. 3b, the maximum steepness $\left|d T / d\left(f_{S}\right)^{1 / 2}\right|$ of the $T-\left(f_{S}\right)^{1 / 2}$ curves is reduced by diffusion. For instance, as indicated by the two red lines, for alloy $\mathrm{Al}-1 \mathrm{Cu}$ the steepness of the tangent at $\left(f_{S B}\right)^{1 / 2}$ $=0.99$ is lower with diffusion $(\alpha=0.05)$ than without $(\alpha=0)$.

The effect of diffusion on the crack susceptibility curve of Al-Cu alloys is shown in Fig. 3c. The crack susceptibility curve is the curve of the maximum steepness $\left|d T / d\left(f_{S}\right)^{1 / 2}\right|$ of the $T$ $\left(f_{S}\right)^{1 / 2}$ curve vs. the solute content of the alloy. As shown in Fig. 3c, with increasing diffusion from $\alpha=0.00$ to 0.05 , the height of the peak decreases and the position of the peak shifts toward higher $\mathrm{Cu}$ contents. This effect of diffusion is similar to that shown previously by the analytical equation based on straight liquidus and solidus lines [16]. However, with straight liquidus and solidus lines the peaks are lower, e.g., about $0.92 \times 10^{40} \mathrm{Cat} \alpha=0.00,0.65 \times 10^{40} \mathrm{Cat} \alpha=0.025$, and $0.50 \times 10^{40} \mathrm{Cat} \alpha=0.05$. The higher peaks with the curved liquidus line are caused by the reduction in the equilibrium segregation coefficient $k$, which causes more solute segregation to promote the crack susceptibility. The peaks observed in crack susceptibility testing of binary Al$\mathrm{Cu}$ alloys include: about $1 \mathrm{wt} \% \mathrm{Cu}$ in casting by Novikov et al. [24] and Spittle et al. [25], $3 \mathrm{wt} \%$ $\mathrm{Cu}$ in welding by Pumphrey et al. [13] and Cross et al. [15], and $5 \mathrm{wt} \% \mathrm{Cu}$ in sand casting by Rosenberg et al. [14]. The rather slow cooling rate in casting in a sand mold favors a larger $\lambda_{2}$ and $t_{f}$, which are likely to increase $\alpha$ to beyond 0.05 . Thus, the peak of Rosenberg et al. [14] is not included in Fig. 3c for comparison with results based on $\alpha=0.025$ and 0.05 .

\section{Al-Mg alloys}


The case of Al-Mg alloys is shown in Fig. 4. The Al-Mg phase diagram in Fig. 4a shows that $T_{E}=450{ }^{\circ} \mathrm{C}$ and $k=0.45(=15.19 / 33.75)$ at $T_{E}$. As shown in Fig. 4a, the liquidus and solidus lines are both curved, widening the two-phase region of $(\mathrm{S}+\mathrm{L})$ and hence making $k$ smaller than that based on the approximation of straight liquidus and solidus lines. The effect of diffusion on $T-\left(f_{S}\right)^{1 / 2}$ curves is shown in Fig. $4 \mathrm{~b}$. Diffusion $(\alpha=0.05)$ makes the $T-\left(f_{S}\right)^{1 / 2}$ curves significantly shallower especially for alloys below about $5 \mathrm{wt} \% \mathrm{Mg}$, thus reducing the maximum steepness $\left|d T / d\left(f_{S}\right)^{1 / 2}\right|$ of the $T-\left(f_{S}\right)^{1 / 2}$ curves. For instance, as shown by the two red lines for alloy Al$3 \mathrm{Mg}$, the steepness of the tangent is lower with diffusion (at $\alpha=0.05$ and $\left.\left(f_{S B}\right)^{1 / 2}=0.99\right)$ than without (at $\alpha=0$ and $T_{E}$ ).

The effect of diffusion on the crack susceptibility curve of Al-Mg alloys is shown in Fig. 4c. Again, diffusion reduces the height of the peak and shifts the position of the peak toward higher solute contents. With straight liquidus and solidus lines the peaks are about $1.1 \times 10^{40} \mathrm{Cat}$ $\alpha=0.00,0.5 \times 10^{40} \mathrm{Cat} \alpha=0.025$ and $0.3 \times 10^{40} \mathrm{Cat} \alpha=0.05$ [16], which are lower than the peaks shown in Fig. 4c. The peaks observed in crack susceptibility testing of binary Al-Mg alloys include: about $2 \mathrm{wt} \% \mathrm{Mg}$ in welding by Dowd [26] and Cross et al. [15], $4 \mathrm{wt} \% \mathrm{Mg}$ in welding by Pumphrey et al. [13] and $5 \mathrm{wt} \% \mathrm{Mg}$ in sand casting by Rosenberg et al. [14]. Again, the peak observed in sand casting is not included in Fig. $4 \mathrm{c}$ for comparison with results based on $\alpha=0.025$ and 0.05 .

Comparison between Fig. $3 \mathrm{c}$ and Fig. 4c shows that diffusion reduces the crack susceptibility more significantly in Al-Mg alloys than Al-Cu alloys. Without diffusion $(\alpha=0.00)$ the peak of the crack susceptibility is higher for Al-Mg alloys $\left(1.4 \times 10^{40} \mathrm{C}\right)$ than for $\mathrm{Al}-\mathrm{Cu}$ alloys $\left(1.2 \times 10^{40} \mathrm{C}\right)$. With diffusion, however, the opposite is true, that is, $0.6 \times 10^{40} \mathrm{C}$ at $\alpha=0.025$ and $0.4 \times 10^{40} \mathrm{C}$ at $\alpha=0.05$ for Al-Mg alloys (Fig. $4 \mathrm{c}$ ) and $0.8 \times 10^{4 \circ} \mathrm{C}$ at $\alpha=0.025$ and $0.7 \times 10^{40} \mathrm{C}$ at 
$\alpha=0.05$ for Al-Cu alloys (Fig. 3c). Thus, diffusion can explain why Al-Mg alloys, despite their significantly wider freezing temperature range than $\mathrm{Al}-\mathrm{Cu}$ alloys, still have better weldability than $\mathrm{Al}-\mathrm{Cu}$ alloys [13-15]. This also confirms that back diffusion can occur in $\mathrm{Al}$ arc welding. It can be seen from Eqs. (2) and (9) that diffusion affects the solidification path $f_{S}(T)$ through $\alpha k$ and not $k$ alone. Thus, the effect of diffusion on $\left|d T / d\left(f_{S}\right)^{1 / 2}\right|$ and hence the crack susceptibility can be expected to be more significant for Al-Mg $\left(k=0.45\right.$ at $\left.T_{E}\right)$ than $\mathrm{Al}-\mathrm{Cu}\left(k=0.17\right.$ at $\left.T_{E}\right)$.

\section{Al-Zn alloys}

Fig. 5 shows the case of Al-Zn alloys. As shown in Fig. 5a, the binary Al-Zn phase diagram has a very low eutectic temperature $T_{E}$ of $382^{\circ} \mathrm{C}$. More interestingly, it has an extremely high $C_{S M}$ of $82.95 \mathrm{wt} \% \mathrm{Zn}$ and $k$ of $0.87(82.95 / 95.19)$ at $T_{E}$. The liquidus and solidus lines are both highly curved. Obviously, the approximation of straight liquidus and solidus lines can lead to serious errors in calculating $T-\left(f_{S}\right)^{1 / 2}$ and crack-susceptibility curves. This is why the numerical integration approach proposed in the present study is needed.

Fig. 5b shows $T-\left(f_{S}\right)^{1 / 2}$ curves for Al-Zn alloys. Without diffusion $(\alpha=0.00)$ the maximum steepness $\left|d T / d\left(f_{S}\right)^{1 / 2}\right|$ of the curves is very high mainly because of the very wide freezing temperature range $\left(T_{m}-T_{E}\right)$ and the very small amount of liquid left at $T_{E}$. Thus, without diffusion the susceptibility to cracking can be expected to be very high, higher than that of $\mathrm{Al}-\mathrm{Cu}$ and Al-Mg alloys. This is confirmed by the crack susceptibility curve at $\alpha=0.00$ shown in Fig. 5c. The height of the peak is about $1.6 \times 10^{40} \mathrm{C}$, as compared to that of $1.2 \times 10^{40} \mathrm{C}$ for $\mathrm{Al}-\mathrm{Cu}$ alloys (Fig. 3c) and $1.4 \times 10^{40} \mathrm{C}$ for Al-Mg alloys (Fig. 4c).

However, as shown in Fig. 5 b, with diffusion at $\alpha=0.05$ the $T-\left(f_{S}\right)^{1 / 2}$ curves become much shallower. No liquid at $T_{E}$ means no eutectic in the solidified alloys. The absence of eutectic was confirmed by Pumphrey and Lyons [13] in ring casting and welding of Al-Zn alloys 
up to $20 \mathrm{wt} \% \mathrm{Zn}$. The solidified alloys consisted entirely of the Al-rich solid solution (Al), which confirms that back diffusion can occur in Al welding.

Since the maximum steepness $\left|d T / d\left(f_{S}\right)^{1 / 2}\right|$ of the curves becomes much smaller, diffusion can be expected to reduce the crack susceptibility significantly. As shown in Fig. 5c, the crack susceptibility curves at $\alpha=0.025$ and 0.05 are significantly lower than that at $\alpha=0.00$. The two curves with diffusion rise with rising $\mathrm{Zn}$ content up to $20 \mathrm{wt} \% \mathrm{Zn}$. The crack susceptibility curve of Pumphrey and Lyons [13] up to $20 \mathrm{wt} \% \mathrm{Zn}$ showed the crack susceptibility increased with increasing $\mathrm{Zn}$ content up to $20 \mathrm{wt} \% \mathrm{Zn}$. This again confirms that back diffusion can occur in Al welding. The ring casting data of Pumphrey and Lyons [13] showed the Al-Zn alloy system is less crack susceptible than the $\mathrm{Al}-\mathrm{Cu}$ alloy system. As mentioned previously, the influence of diffusion on the solidification path $f_{S}(T)$ is through $\alpha k$ and not $k$ alone according to Eq. (2) and (9). Thus, the effect of diffusion on $\left|d T / d\left(f_{S}\right)^{1 / 2}\right|$ and hence the crack susceptibility can be expected to be significantly greater for Al-Zn $\left(k=0.87\right.$ at $\left.T_{E}\right)$ than for $\mathrm{Al}-\mathrm{Mg}\left(k=0.45\right.$ at $\left.T_{E}\right)$ and $\mathrm{Al}-\mathrm{Cu}\left(k=0.17\right.$ at $\left.T_{E}\right)$.

\section{Al-Sn alloys}

The case of Al-Sn alloys is shown in Fig. 6. As shown in Fig. 6a, the binary Al-Sn phase diagram is very unusual. It shows a very low eutectic temperature $T_{E}$ of $229^{\circ} \mathrm{C}$, an extremely curved liquidus line, a nearly straight solidus line of essentially no solute solubility $(k \approx 0)$, and a eutectic close to pure Sn. Obviously, the approximation of a straight liquidus line can be expected to cause serious errors in calculating $T-\left(f_{S}\right)^{1 / 2}$ and crack-susceptibility curves.

Fig. 6b shows $T-\left(f_{S}\right)^{1 / 2}$ curves of Al-Sn alloys. They were calculated with the highly curved liquidus line and a straight solidus line with a maximum solubility of $0.1 \mathrm{wt} \% \mathrm{Sn}$. As shown, the $T-\left(f_{S}\right)^{1 / 2}$ curves are identical with or without diffusion. This is because there is 
essentially no solubility of Sn in solid Al. The maximum steepness $\left|d T / d\left(f_{S}\right)^{1 / 2}\right|$ of the curves is extremely high mainly because of the very wide freezing temperature range $\left(T_{m}-T_{E}\right)$ and the nearly vertical liquidus and solidus lines over a wide temperature range before $T_{E}$ (about 500 to $229{ }^{\circ} \mathrm{C}$ ), which keeps $f_{S}$ from increasing with decreasing $T$ in the temperature range. Thus, the susceptibility to cracking can be expected to be very high. This is consistent with the crack susceptibility tests of Rosenberg et al. [14], which showed that Al-Sn alloys are highly crack susceptible, more susceptible than $\mathrm{Al}-\mathrm{Cu}$ and $\mathrm{Al}-\mathrm{Mg}$ alloys. Diffusion cannot help reduce the crack susceptibility of Al-Sn alloys because there is essentially no solubility of Sn in solid Al.

Fig. $6 \mathrm{c}$ shows two sets of the crack susceptibility curves, one with $\left(f_{S B}\right)^{1 / 2}=0.99\left(f_{S B}=\right.$ $0.98)$ as in the cases of $\mathrm{Al}-\mathrm{Cu}, \mathrm{Al}-\mathrm{Mg}$ and $\mathrm{Al}-\mathrm{Zn}$ alloys, and the other with $\left(f_{S B}\right)^{1 / 2}=0.996\left(f_{S B}=\right.$ 0.992). Each set consists of three identical curves of $\alpha=0.00,0.025$ and 0.05 . As mentioned previously, $f_{S B}$ represents the fraction solid at which extensive bridging between grains occurs to bond them together firmly to resist cracking. According to the data of Rosenberg et al. [14], high crack susceptibility occurred in Al-Sn alloys in the composition range of 0.75 to $4.33 \mathrm{wt} \% \mathrm{Sn}$. Thus, the crack susceptibility is already high at $1 \mathrm{wt} \% \mathrm{Sn}$. This is inconsistent with the crack susceptibility curve based on $\left(f_{S B}\right)^{1 / 2}=0.99$. By raising $\left(f_{S B}\right)^{1 / 2}$ to 0.996 , the crack susceptibility curve shows high crack susceptibility in this composition range. Notice that in Fig. 6c the crack susceptibility index is shown in $10^{6}{ }^{\circ} \mathrm{C}$ instead of $10^{4}{ }^{\circ} \mathrm{C}$ as in the cases of $\mathrm{Al}-\mathrm{Cu}, \mathrm{Al}-\mathrm{Mg}$ and $\mathrm{Al}-$ Zn alloys.

\section{Dihedral angle and bridging}

It is commonly accepted that the dihedral angle [27] can affect the susceptibility of an alloy to cracking during solidification. A smaller dihedral angle is associated with the greater tendency to form thin continuous liquid films between grains to separate them and promote 
intergranular cracking. Fig. 7 shows an attempt to link the dihedral anglewith bridging between grains. Consider the transverse cross-section of three neighboring columnar grains near $\left(f_{S}\right)^{1 / 2}=$ 1. Suppose the surface tension effect and the fraction of liquid are such that the grains are still able to remain cylindrical in transverse cross-section. As illustrated in Fig. 7a, the grains just touch each other to initiate bridging. Since the liquid within each grain is negligible near $\left(f_{S}\right)^{1 / 2}=$ 1 [6], the total transverse cross-sectional area of the grains divided by that of the hexagons enveloping them can be considered as the fraction solid $f_{S}$. In this special case $f_{S}=0.907$ or $\left(f_{S}\right)^{1 / 2}$ $=0.952$. Since the cross-section of the liquid left in the closed space between the three grains is relatively large and essentially triangular, the cross-section of the resultant eutectic may also be more or less triangular as illustrated in Fig. $7 \mathrm{~b}$, and the dihedral angle may be substantial. The eutectic in the $\mathrm{Al}-5 \mathrm{Cu}$ casting in Fig. $7 \mathrm{c}$ may be considered as an example of a substantial dihedral angle [28]. The sample was quenched during solidification at the eutectic temperature to preserve the liquid eutectic.

On the contrary, suppose the surface tension effect and the fraction of liquid are such that the three grains have already become nearly hexagonal in cross-section at $f_{S}=0.907$ or $\left(f_{S}\right)^{1 / 2}=$ 0.952 as illustrated in Fig. 7 d. As shown, no bridging has occurred yet because the same amount of liquid is now distributed over the entire grain boundary area. As the fraction solid increases further the grain boundary liquid can become very thin and yet still continuous if: 1 . the liquid solute content is very high, 2. the solute does not diffuse away from the liquid, and 3. the liquid does not solidify until a very low temperature. If so, extensive bridging can be delayed until almost the very end of solidification, e.g., $f_{S B}=0.992$ or $\left(f_{S B}\right)^{1 / 2}=0.996$. The resultant dihedral angle can be much smaller as illustrated in Fig. 7e. The eutectic in the Al-5Sn casting in Fig. $7 \mathrm{f}$ may be considered as such an example. The eutectic in the Al-2Sn casting in Fig. $7 \mathrm{~g}$ shows even 
thinner eutectic films [28]. Again, both samples were quenched during solidification at the eutectic temperature to preserve the liquid eutectic. Thin continuous liquid films can keep staying because: 1 . the liquid $\mathrm{Sn}$ content is very high $\left(C_{E}=99.58 \mathrm{wt} \% \mathrm{Sn}\right), 2$. Sn has essentially no solubility in solid Al to diffuse away into Al-rich dendrites, and 3. thefreezing temperature of the liquid is very low $\left(T_{E}=229^{\circ} \mathrm{C}\right)$. Similar thin eutectic films in Al-Sn alloys were reported by Rosenberg et al. [14] even in sand casting, where the cooling rate is slow. Fig. 7 may explain why bridging in Al-Sn is delayed, that is, $\left(f_{S B}\right)^{1 / 2}=0.996$ (Fig. 6), as compared to most other Al alloys such as Al-Cu, Al-Mg and Al-Zn, that is, $\left(f_{S B}\right)^{1 / 2}=0.99$ (Figs. 3 through 5). Thus, a more significantly delayed extensive bridging, that is, a $\left(f_{S B}\right)^{1 / 2}$ closer to 1.0 , seems to be associated with a smaller dihedral angle and a higher crack susceptibility.

Borland [29] pointed out that a small dihedral angle is associated with high wettability of grains by the grain boundary liquid, that is, the grain boundary liquid between two neighboring grains tends to form a continuous film covering the grain faces, separating the grains and thus promoting high crack susceptibility. Rogerson and Borland [30] studied the crack susceptibility of Al-Sn, Al-Cd and Al-In alloys in welding and casting. The found that Al-Sn alloys, which gave the lowest dihedral angles, showed the greatest severity of cracking in both welds and castings. These are consistent with the delayed extensive bridging illustrated in Fig. 7 which, as mentioned previously, is associated with a small dihedral angle and a high crack susceptibility. One contradictory effect of the high wettability associated with a low dihedral angle, however, is enhanced liquid feeding of shrinkage, which should work to improve crack resistance.

\section{Conclusions}

1. A numerical integration approach has been developed to calculate the crack susceptibility, based on the maximum $\left|d T / d\left(f_{S}\right)^{1 / 2}\right|$ as the crack susceptibility index, 
enabling all binary alloys to be studied instead of only those with a constant equilibrium segregation coefficient $k$ (straight liquidus and solidus lines).

2. Back diffusion can occur in arc welding of Al alloys, at the level of $\alpha=0.025$ to 0.050 based on the welding data that show $\lambda_{2}=10$ to $20 \mu \mathrm{m}$ in common $\mathrm{Al}$ arc welds and the solidification data that correlate $\lambda_{2}$ with $t_{f}$ in Al alloys.

3. Since the solidification path $f_{S}(T)$ is affected by back diffusion through $\alpha k$ and not $\alpha$ alone, as can be seen in Eqs. (2) and (9), the effect of back diffusion on the maximum $\left|d T / d\left(f_{S}\right)^{1 / 2}\right|$ and hence the crack susceptibility can be expected to be significantly greater for Al-Mg $\left(k=0.45\right.$ at $\left.T_{E}\right)$ and $\mathrm{Al}-\mathrm{Zn}\left(k=0.87\right.$ at $\left.T_{E}\right)$ than for $\mathrm{Al}-\mathrm{Cu}(k=0.17$ at $\left.T_{E}\right)$.

4. A binary $\mathrm{Al}$ alloy system with a very low $T_{E}$ (that is, a very wide freezing temperature range of $T_{L}$ to $T_{E}$ ) but a very high $k$ at $T_{E}$ can still have a relatively low crack susceptibility because of back diffusion, which is consistent with the reported lower crack susceptibility of Al- $\mathrm{Mg}\left(T_{E}=450{ }^{\circ} \mathrm{C}\right)$ and even $\mathrm{Al}-\mathrm{Zn}\left(T_{E}=382{ }^{\circ} \mathrm{C}\right)$ than $\mathrm{Al}-\mathrm{Cu}$ $\left(T_{E}=548^{\circ} \mathrm{C}\right)$.

5. A binary Al alloy system with both a very low $T_{E}$ and a very low $k$ at $T_{E}$ can be highly crack susceptible, which is consistent with the reported severe crack susceptibility of $\operatorname{Al}-\operatorname{Sn}\left(T_{E}=229{ }^{\circ} \mathrm{C}, k \approx 0\right.$ at $\left.T_{E}\right)$.

6. The extensive bridging of grains needed to resist cracking is delayed in the case of $\mathrm{Al}-\mathrm{Sn}$ as compared to $\mathrm{Al}-\mathrm{Cu}, \mathrm{Al}-\mathrm{Mg}$ and $\mathrm{Al}-\mathrm{Zn}$, which is consistent with the much higher crack susceptibility of Al-Sn (even at $1 \mathrm{wt} \% \mathrm{Sn}$ ) and with the thin continuous eutecticobserved along grain boundaries of Al-Sn, which suggests a small diahedral angle. 
7. A liquidus or solidus line that deviates from a straight line in such a way as to widen the two-phase region of $(\mathrm{S}+\mathrm{L})$ in the phase diagram tends to decrease $k$, increase solute segregation and hence increase the crack susceptibility.

\section{Acknowledgements}

This work was supported by the National Science Foundation under Grant No. DMR 1500367. The coauthor Liu was supported by the China Scholarship Council as a visiting graduate student at the University of Wisconsin-Madison. The authors thank CompuTherm, LLC, Madison, WI for kindly providing Pandat 2014 and PanAluminum 2014 for calculating the phase diagrams.

\section{References}

[1] S. Kou, Welding Metallurgy, second ed., John Wiley and Sons, Hoboken, 2013, 257300.

[2] M.C. Flemings, Solidification Processing, McGraw-Hill, New York, 1974, 252-256, Appendix.

[3] J. Campbell, Castings, 2nd ed., Butterworth Heinemann, Oxford, 2003, 216-247.

[4] J. Campbell, Complete Casting Handbook, 2nd ed., Butterworth Heinemann, Oxford, 2015, 21-30 and 444-445.

[5] M. Rappaz, J.M. Drezet, M. Gremaud, A new hot-tearing criterion, Metall. Mater. Trans. 30A (1999) 449-455.

[6] S. Kou, A criterion for cracking during solidification, Acta Mater. 88 (2015) 366-374.

[7] N. Coniglio and C. E. Cross, "Mechanisms for solidification cracking initiation and growth in aluminum welding," Metallurgical and Materials Transactions, 40A (2009) 2718-2728. 
[8] J. Campbell, Private communications, United Kingdom, June, 2014.

[9] S. Kou, Transport Phenomena and Materials Processing, John Wiley and Sons, Hoboken, $1996,64-67$.

[10] Pandat - Phase Diagram Calculation software package for Multicomponent Systems, Computherm LLC, Madison, WI 53719, 2001.

[11] PanAluminium - Thermodynamic database for Commercial Aluminum Alloys, Computherm LLC, Madison, WI 53719, 2001.

[12] S. Kou, A simple index for predicting the susceptibility to solidification cracking in welding, Welding Journal, 94 (2015) 374s-388s.

[13] W.I. Pumphrey, J.V. Lyons, Cracking during the casting and welding of the more common binary aluminium alloys, J. Inst. Metals 74 (1948) 439-455.

[14] R. A. Rosenberg, M.C. Flemings, H. F. Taylor, Nonferrous binary alloys hot tearing, Transactions of American Foundry Society, 68(1960) 518-528.

[15] C. E. Cross, D. L. Olson, Hot tearing model to assess aluminum weldability, in Aluminum Alloys Their Physical and Mechanical Properties, vol. III, Conference Proceedings, Charlotsville, VA, 1986, pp. 1869-1875.

[16] J. Liu and S. Kou, Effect of diffusion on susceptibility to cracking during solidification, Acta Mater. 100 (2015) 359-368.

[17] W. Kurz and D.J. Fisher, Fundamentals of Solidification, $4^{\text {th }}$ ed., Trans Tech Publications, Aedermannsdorf, Switzerland, 1998, pp. 234-235.

[18] Getdata Graph Digitizer,http://www.getdata-graph-digitizer.com/registration.php.

[19] R. N. Grugel, Secondary and tertiary dendrite arm spacing relationships in directionally solidified Al-Si alloys, Journal of Materials Science, 28 (1993) 677-683. 
[20] K. P. Young and D. H. Kirkwood, The Dendrite Arm Spacings of Aluminum-Copper Alloys Solidified Under Steady-State Conditions, Metallurgical Transactions, 6A(1975) 197-205.

[21] M. Chen and T. Z. Kattamis, Dendrite coarsening during directional solidification of Al-Cu-Mn alloys, Materials Science and Engineering, A247 (1998) 239-247.

[22] D.R. Poirier, G.H. Geiger, Transport Phenomena in Materials Processing, TMS Publications, Warrendale PA, 1994, p. 432.

[23] T.W. Clyne, G.J. Davies, Influence of composition on solidification cracking susceptibility in binary alloy systems, Br. Foundryman 74 (4) (1981) 65-73.

[24] I.I. Nivikov, Hot shortness of non-ferrous metals and alloys,Russ. Cast. Prod. 4 (1962) $167-172$.

[25] J.A. Spittle, A.A. Cushway, Influences of superheat and grain structure on hot-tearing susceptibilities of Al-Cu alloy castings, Metal Technol. 10 (1983) 6-13.

[26] J.D. Dowd, Weld cracking of aluminum alloys, Welding Journal 1952(31) 448s-456s.

[27] C.S. Smith, Grains, phases, and interfaces - an interpretation of microstructure, Trans AIME, 175 (1948) 15-51.

[28] Y. Ju, L. Arnberg, Measurement of bridging in some Al-Cu and Al-Sn alloys, International Journal of Cast Metal Research 16 (2003) 522-530.

[29] J.C. Borland, Generalized Theory of Super-Solidus Cracking in Welds and Castings: An Initial Development, British Welding Journal, 7 (1960) 508-512.

[30] J.H. Rogerson and J.C. Borland, Effect of the Intergranular Liquid on the Hot Cracking of Welds and Castings, Trans. AIME, 227 (1963) 2-7. 
Table 1 Estimation of $\alpha=0.025-0.050$ for Al arc welding based on $\lambda_{2}=10-20 \mu \mathrm{m}$ in common $\mathrm{Al}$ arc welds [16] and data of Al alloys [2, 19-21] showing that $\lambda_{2}=10-20 \mu \mathrm{m}$ corresponds approximately to $t_{f}=1-7 \mathrm{~s}$, which is close to the range of $t_{f}=0.625-5 \mathrm{~s}$ shown in the table.

\begin{tabular}{|l|l|l|l|}
\hline $\begin{array}{l}\text { Diffusion } \\
\text { coefficient } \\
D_{S}[22]\end{array}$ & $\begin{array}{l}\text { Diffusion parameter } \\
\alpha=\left(4 D_{S} t_{f}\right) /\left(\lambda_{2}\right)^{2} \\
\text { Eq. (5) }\end{array}$ & $\begin{array}{l}2^{\text {nd }} \text { dendrite arm } \\
\text { spacing } \lambda_{2} \\
\text { commonin Al arc } \\
\text { welds }\end{array}$ & $\begin{array}{l}\text { Local solidification } \\
\text { time } t_{f} \text { based on Eq. } \\
(5)\end{array}$ \\
\hline \multirow{3}{*}{$1 \times 10^{-12} \mathrm{~m}^{2} / \mathrm{s}$} & 0.025 & $10 \mu \mathrm{m}$ & $0.625 \mathrm{~s}$ \\
\cline { 2 - 4 } & 0.050 & $20 \mu \mathrm{m}$ & $2.50 \mathrm{~s}$ \\
\cline { 3 - 4 } & $10 \mu \mathrm{m}$ & $1.25 \mathrm{~s}$ \\
\cline { 2 - 4 } & $20 \mu \mathrm{m}$ & $5.00 \mathrm{~s}$ \\
\hline
\end{tabular}




\section{Figure Captions}

Fig. $1\left|d T / d\left(f_{S}\right)^{1 / 2}\right|$ near $\left(f_{S}\right)^{1 / 2}=1$ as crack susceptibility index [6]: (a) a high index promotes crack susceptibility by reducing $d R / d t$; (b) $d R / d t$ decreases with increasing $\left|d T / d\left(f_{S}\right)^{1 / 2}\right|$. Grain-boundary channel can be long to resist flow through it if, due to small $d R / d t$, grains grow much more slowly laterally than axially.

Fig. 2 Effect of liquidus line curvature: (a) binary Al-Cu phase diagram; (b) curves of $T$ vs. $\left(f_{S}\right)^{1 / 2}$ based on straight liquidus line as approximation; (c) a slight curvature causing significant differences. Extensive bridging between grains is assumed to occur at $\left(f_{S B}\right)^{1 / 2}=0.99$ to resist cracking. In (b) tangents (red lines) show maximum steepness of curves before and at 0.99 , and curve of most crack susceptible alloy (highest maximum steepness) passes through intersection between $T_{E}$ and 0.99 . No back diffusion $(\alpha=0)$.

Fig. 3 Binary Al-Cu alloys: (a) phase diagram; (b) $T-\left(f_{S}\right)^{1 / 2}$ curves without diffusion $(\alpha=0)$ and with diffusion (at $\alpha=0.05$ ); (c) crack susceptibility curves based on maximum steepness $\left|d T / d\left(f_{S}\right)^{1 / 2}\right|$ as crack susceptibility index. With straight liquidus and solidus lines, peaks are lower, i.e., $0.92 \times 10^{40} \mathrm{C}$ at $\alpha=0,0.65 \times 10^{40} \mathrm{C}$ at $\alpha=0.025$, and $0.50 \times 10^{40} \mathrm{C}$ at $\alpha=$ $0.05[16]$.

Fig. 4 Binary Al-Mg alloys: (a) phase diagram showing slightly curved liquidus and solidus lines; (b) $T-\left(f_{S}\right)^{1 / 2}$ curves; (c) crack susceptibility curves. With straight liquidus and solidus lines, peaks are lower, i.e., $1.1 \times 10^{40} \mathrm{Cat} \alpha=0,0.5 \times 10^{40} \mathrm{Cat} \alpha=0.025$ and $0.3 \times 10^{4 \circ} \mathrm{Cat}$ $\alpha=0.05[16]$.

Fig. 5 Binary Al-Zn alloys: (a) phase diagram showing highly curved liquidus and solidus lines; (b) $T-\left(f_{S}\right)^{1 / 2}$ curves; (c) crack susceptibility curves. (b) (c) consistent with Pumphrey and Lyons [13]. 
Fig. 6 Binary Al-Sn alloys: (a) phase diagram showing extremely curved liquidus line; (b) $T$ $\left(f_{S}\right)^{1 / 2}$ curves (distortion caused by changes in liquidus slope around $600{ }^{\circ} \mathrm{C}$ ); (c) crack susceptibility curves. $\left(f_{S B}\right)^{1 / 2}=0.996$ (very late extensive bridging) is more consistent with crack susceptibility testing [14] than 0.99 .

Fig. 7 Thin grain-boundary eutectic of Al-Sn alloys suggesting very late extensive bridging to aggravate crack susceptibility: (a) example illustrating early initial bridging; (b) example of a relatively large diahedral angle $\theta$; (c) $\mathrm{Al}-5 \mathrm{Cu}$ [28]; (d) example illustrating potentially very late extensive bridging; (e) example of a much smaller $\theta$; (f) (g) Al-Sn alloys [28]. $f_{S}=$ 0.907 or $\left(f_{S B}\right)^{1 / 2}=0.95$ in (a) and (d). 


\section{Graphic abstract}

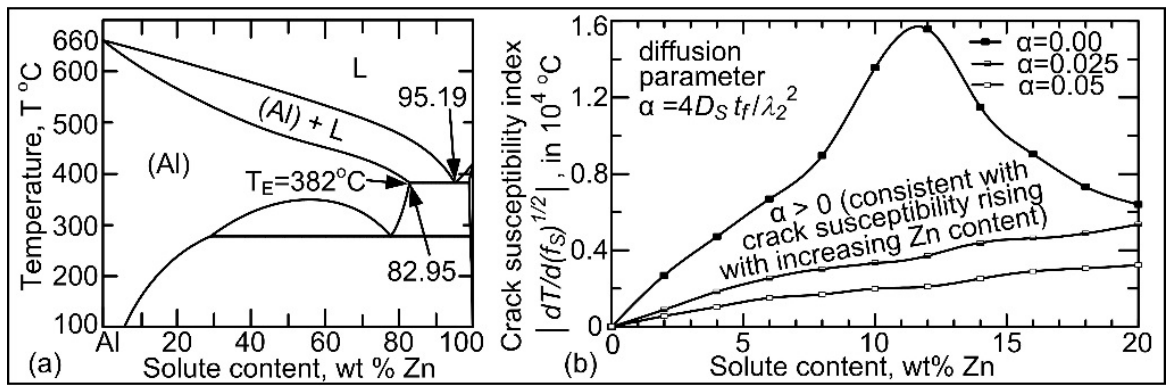

Cracking can occur during solidification in welding and casting. It has been proposed and verified recently that the maximum steepness $\left|d T / d\left(f_{S}\right)^{1 / 2}\right|$ of the curve of temperature Tvs. the square root of fraction $\operatorname{solid} f_{S}$, can be used as the crack susceptibility index. The present study showed thatvariable equilibrium segregation coefficient $k$ and back diffusion can both be considered in calculating the index. Al alloys were studied overa wide range of the eutectic temperature $T_{E}\left(229\right.$ to $\left.548^{\circ} \mathrm{C}\right)$ and $k$ (about0to 0.87 at $\left.T_{E}\right)$, such as Al-Cu, Al-Mg, Al-Zn and AlSn. It was shown that with a large $k$ back diffusion can significantly reduce the crack susceptibility even when the freeing temperature range is very wide due to a very low $T_{E}$. This is consistent with the better crack resistance of $\mathrm{Al}-\mathrm{Mg}$ and even $\mathrm{Al}-\mathrm{Zn}$ than $\mathrm{Al}-\mathrm{Cu}$, which has a much narrower freezing temperature range. The effect of the curvature of the liquidus and solidus lines on the crack susceptibility was shown. A possible link between the dihedral angle and bridging between grains was also shown. 


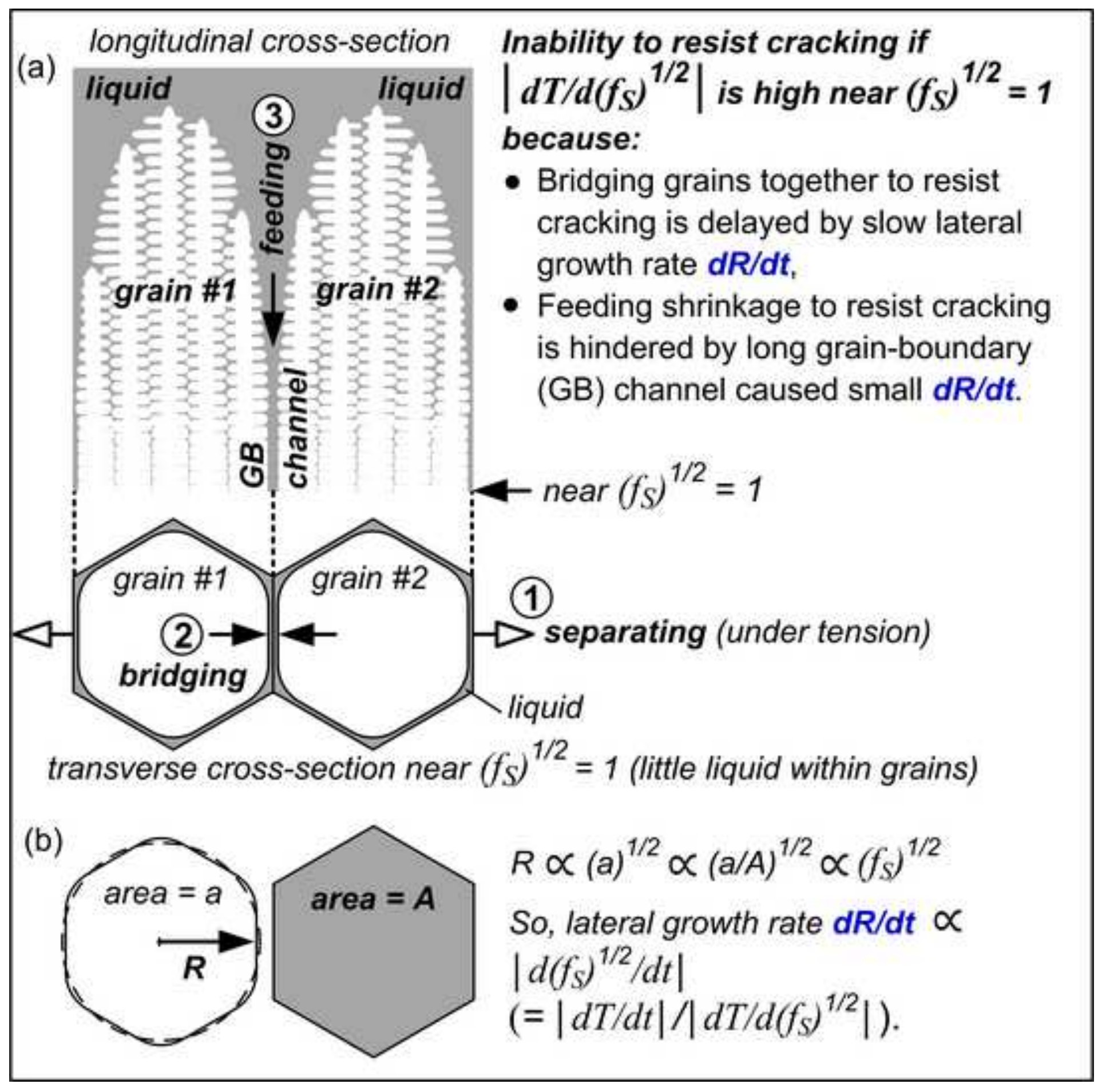




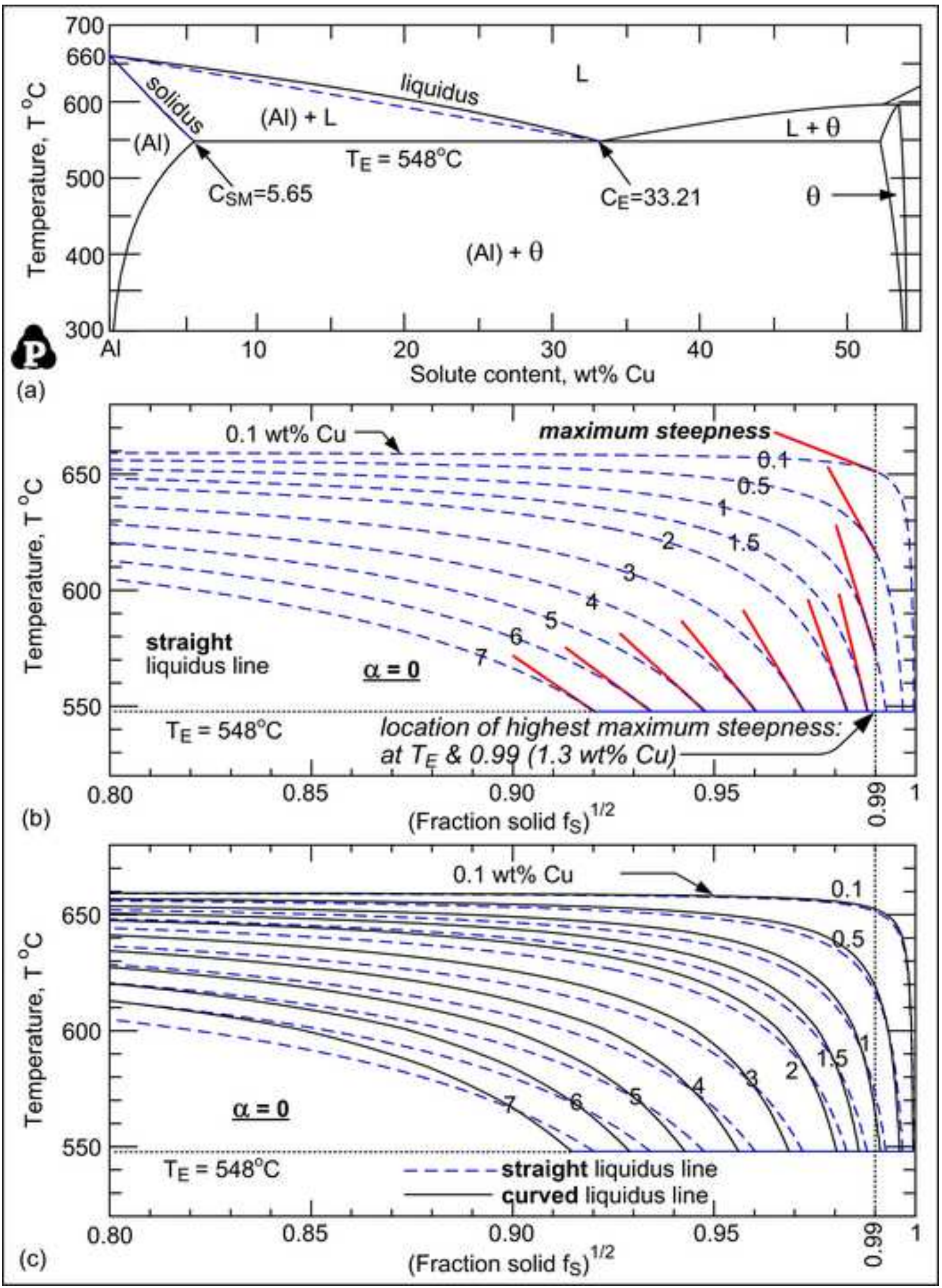




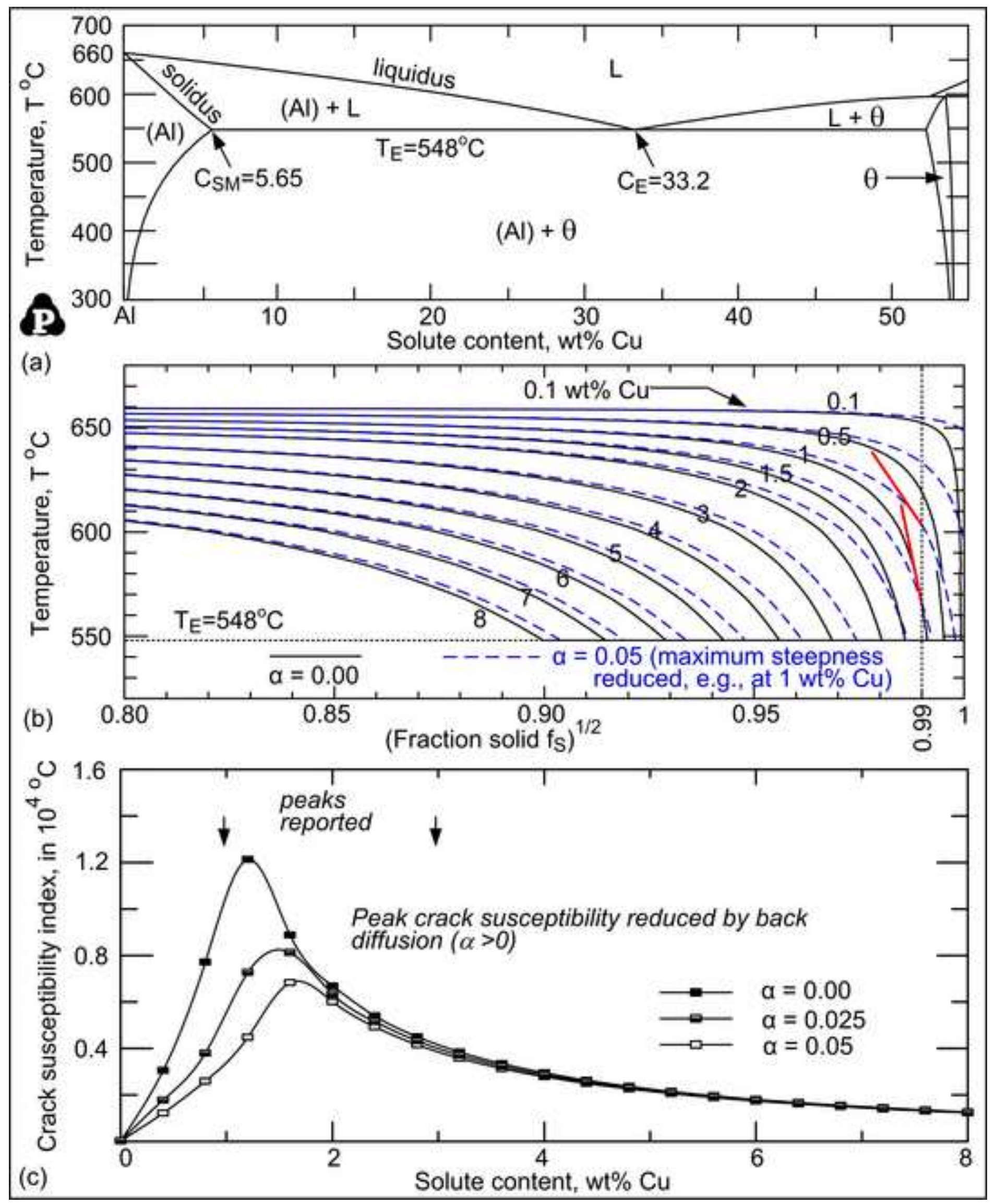




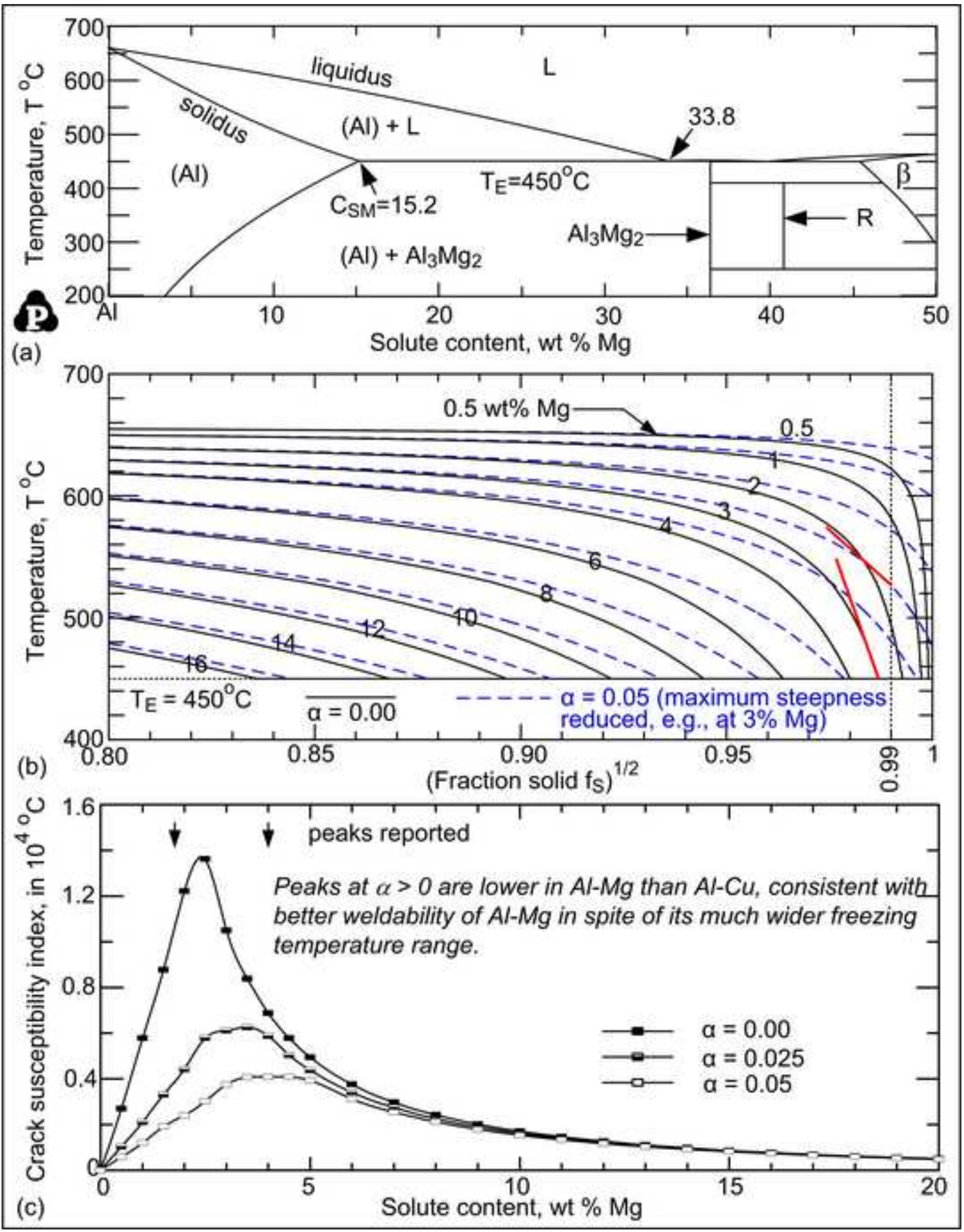



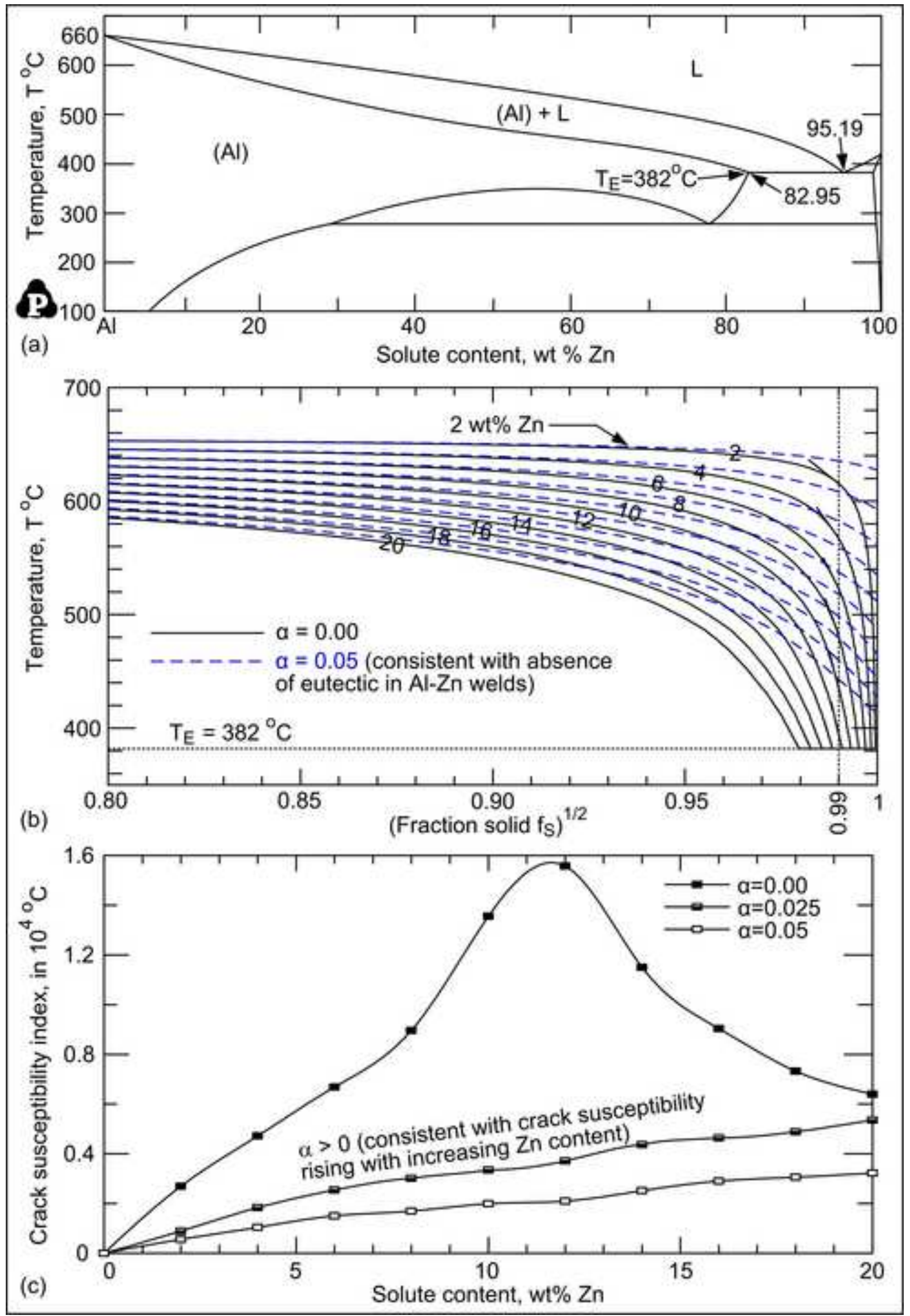


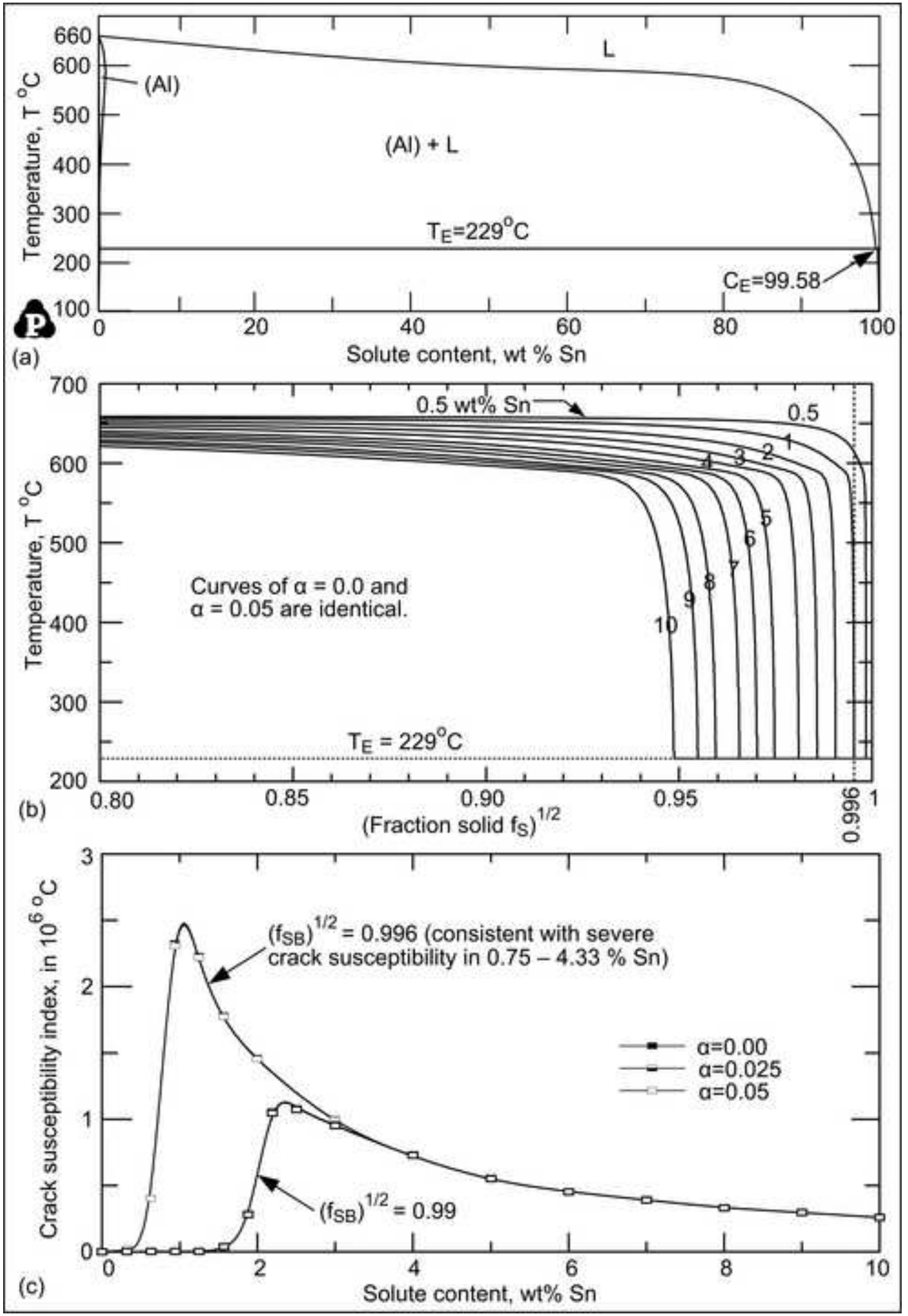




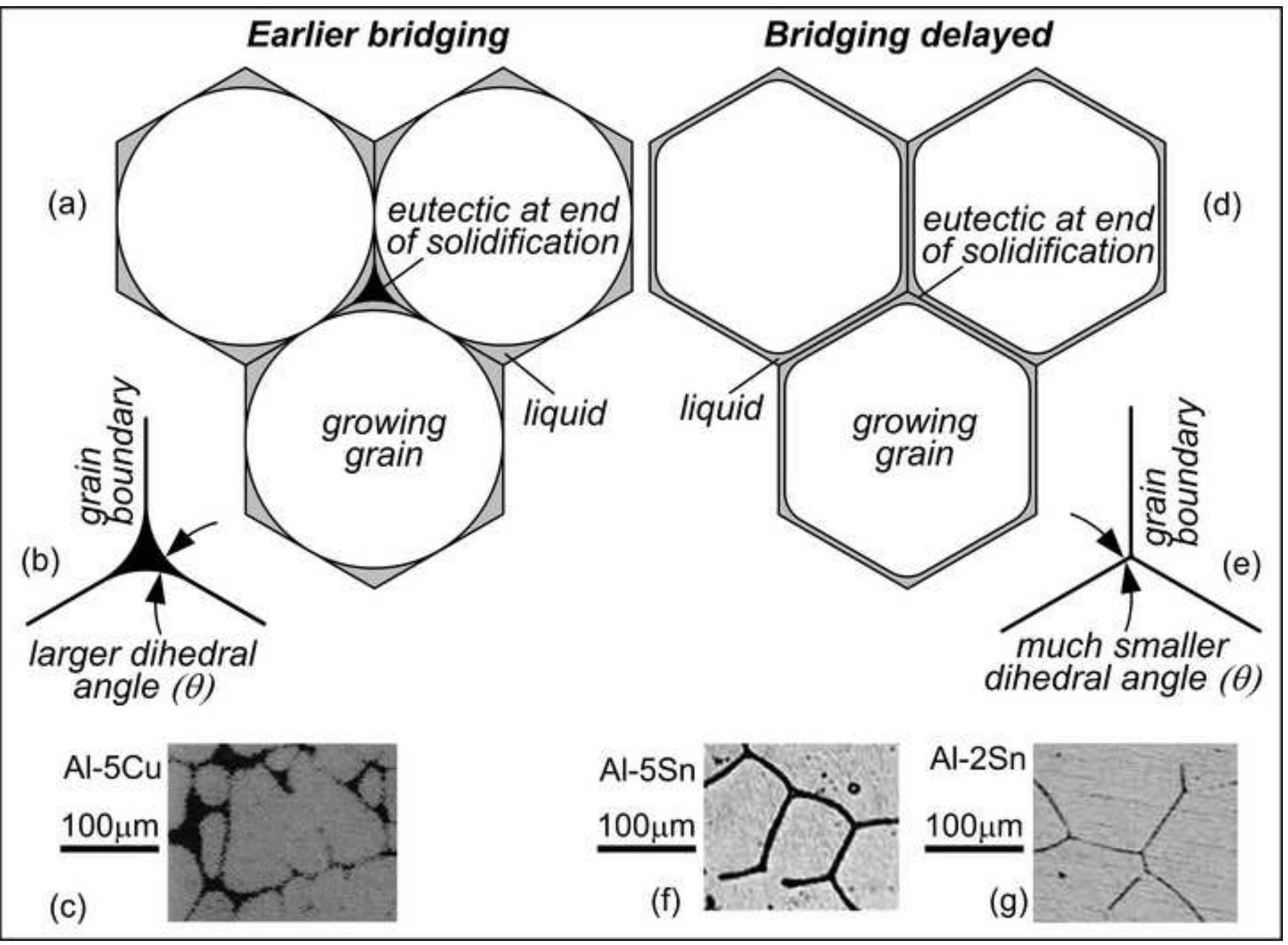

